\title{
Orléans - boulevard Aristide Briand
}

$\mathrm{n}^{\circ} 068191$

\section{Pascal Joyeux}

\section{(2) OpenEdition}

\section{Journals}

Édition électronique

URL : http://journals.openedition.org/adlfi/13863

ISSN : 2114-0502

Éditeur

Ministère de la culture

\section{Référence électronique}

Pascal Joyeux, «Orléans - boulevard Aristide Briand », ADLFI. Archéologie de la France - Informations [En ligne], Centre, mis en ligne le 19 novembre 2014, consulté le 19 avril 2019. URL : http:// journals.openedition.org/adlfi/13863

Ce document a été généré automatiquement le 19 avril 2019

(C) Ministère de la Culture et de la Communication, CNRS 


\section{Orléans - boulevard Aristide Briand}

$n^{\circ} 068191$

\section{Pascal Joyeux}

Lien Atlas (MCC) :

http://atlas.patrimoines.culture.fr/atlas/trunk/index.php?

ap_theme=DOM_2.01.02\&ap_bbox=1.874;47.813;1.949;47.933

1 Le diagnostic sur cette parcelle a permis de mettre en évidence un niveau de silex pouvant correspondre à une place du Haut-Empire. Dans cette hypothèse, elle serait située à environ $200 \mathrm{~m}$ au nord d'une des voies observées dans la cour du lycée SaintEuverte en 1996 (BSR 1996 : 169-170). Aucun niveau postérieur à cet aménagement n’a été observé lors du diagnostic, dans cette zone localisée en dehors de tous les remparts successifs de la ville, et dont l'urbanisation n'est pas antérieure au $\mathrm{XIX}^{\mathrm{e}} \mathrm{s}$. La fouille devrait donc porter sur l'étude du réseau viaire de la période antique.

\section{INDEX}

Index géographique : Centre, Loiret (45), Orléans

Index chronologique : Gallo-romain

Mots-clés : réseau viaire

operation Évaluation archéologique (EV) 